\title{
TRAS LOS PASOS DE LA FORCLUSIÓN DE LACAN: DE LA VERWERFUNG DE FREUD Y OTROS ANTECEDENTES
}

\author{
FOLLOWING THE STEPS OF LACAN'S FORECLOSURE: \\ ABOUT FREUD'S VERWERFUNG AND OTHER \\ PRECEDENTS
}

\author{
Rodrigo Galdames del Solar* \\ Universidad de Tarapacá \\ Iquique-Chile \\ Recibido junio de 2020/Received June, 2020 \\ Aceptado octubre de 2020/Accepted October, 2020
}

\begin{abstract}
RESUMEN
El artículo presenta una investigación teórica que toma al concepto psicoanalítico de forclusión, introducido por Lacan en 1955. como objeto de interrogación. El abordaje de la investigación consideró una genealogía del concepto, tomando como fuentes primarias la elaboración freudiana acerca de la Verwerfung, el forclusif de Pichon y Damourette y los propios desarrollos de Lacan en su seminario y escritos. Respecto del texto freudiano, se demuestra que Freud se refirió a la Verwerfung en tres sentidos que son distintos, pero compatibles, mas que debido al empleo que dio a dicho término en dos trabajos tardíos de 1937 y 1940 , se concluye que no alcanza a configurarse como un concepto freudiano en plenitud.

En cuanto a la trascendencia del forclusif para el concepto de Lacan, se muestra que si bien es cierto Lacan ha extraído el término como resultado de la lectura del trabajo de dichos autores, no hay relación entre los conceptos. Este trabajo permite identificar un nexo más claro entre el forclusif y la Verleugnung de Freud, vía la escotomización de Laforgue (1926; 1927).

Finalmente, este artículo demuestra que la interpretación que conduce a identificar la especificidad de la forclusión respecto de las psicosis no es exacta con los desarrollos de Lacan después de 1960.
\end{abstract}

Palabras Clave: Forclusión, Pichon, Lacan, Freud, Psicoanálisis.

\begin{abstract}
This article presents a theoretical research that takes the psychoanalytic concept of foreclosure, introduced by Lacan in 1955, as an object of question. The research approach considered a genealogy of the concept, taking as primary sources the Freudian elaboration about Verwerfung, Pichon and Damourette's forclusif, and Lacan's own developments in his seminar and writings. Regarding the Freudian text, it is shown that Freud referred to Verwerfung in three ways that are different, but compatible, rather than the use he gave to that term in two late works of 1937 and 1940; it is concluded that it does not reach configuration as a full Freudian concept.

Regarding the significance of forclusif for the concept of Lacan, it is shown that although it is true that Lacan has extracted the term as a result of reading the work of these authors, the concepts are not related. This work allows identifying a clearer link between forclusif and Freud's Verleugnung, through Laforgue's scotomization (1926; 1927).

Finally, this article demonstrates that the interpretation that leads to identify the specificity of foreclosure regarding psychosis is not accurate with the developments of Lacan after 1960.
\end{abstract}

Key Words: Foreclosure, Pichon, Lacan, Freud, Psychoanalysis. 


\section{INTRODUCCIÓN}

El concepto de forclusión, introducido por Lacan en el contexto de su seminario dedicado a las psicosis, constituye en su origen una apuesta de articulación metapsicológica para el entendimiento de la estructura del fenómeno alucinatorio (Lacan, 1955/1984). A partir de ese momento crucial en la elaboración lacaniana de las psicosis, ha transitado en su enseñanza y en el trabajo de los comentadores de su obra, con una amplitud tal, que ha traspasado los bordes del campo de la psicopatología, extendiéndose hasta su teoría de la ciencia (1966/2003a) y sus desarrollos relativos al discurso capitalista (1971).

Forjado en un primer momento, entre febrero de 1954 y julio de 1956 como resultado de su lectura de ciertas elaboraciones freudianas en torno al uso del término Verwerfung, nace como una propuesta de traducción para dicho término, aunque en el curso de su enseñanza logrará consolidarse como un concepto que, por la inexactitud respecto de su origen freudiano y en el marco de un retorno a Freud de la mano de una concepción estructuralista del inconsciente, será luego atribuido a su producción.

¿Puede afirmarse, en efecto, que la forclusión de Lacan constituye un concepto propiamente lacaniano, distinto de la elaboración freudiana de la Verwerfung?, ¿cuál es el sentido que le ha dado Freud a su Verwerfung?, ¿en qué medida puede reconocérsele el estatuto de un concepto y cuánto de ella pervive en la forclusión de Lacan?

Junto a la raíz freudiana, puede reconocerse en un escrito de gramática francesa firmado por Jacques Damourette (1873-1943) y su sobrino, el psicoanalista Edouard Pichon (1890-1940), un antecedente fundamental, por ser el lugar de donde Lacan ha extraído el término. Resulta significativo que Lacan no cite a estos autores en ningún momento de su elaboración acerca de la forclusión, y que, sorprendentemente, sí lo haga al comentar y teorizar respecto de la negación. ¿Cómo puede explicarse esta radical ausencia de la referencia a estos autores? Como ha advertido Arrivé (2004), no solo Lacan suprime la referencia a Damourette y Pichon, pues lo mismo ocurre con Laplanche y Pontalis en su célebre diccionario y con los traductores de Lacan al español: en el caso de los Escritos, Tomás Segovia traduce el término por preclusión, que en el español conserva su fijación al campo jurídico, con lo que se sugiere que Lacan ha recogido el término del Derecho; para la traducción del seminario de las psicosis, Delmont-Mauri y Rabinovich, preservan el galicismo forclusión, aludiendo a la originalidad del uso dado por Lacan, y por constituir ya un "vocablo específicamente psicoanalítico" (1955/1984, p. 457).

Este trabajo, mediante un análisis genealógico que toma, en lo esencial, las raíces freudianas y la gramática de Damourette y Pichon, busca responder las preguntas señaladas y aclarar las coordenadas de la sustitución entre forclusión y Verwerfung.

\section{GÉNESIS FREUDIANA}

Freud utilizó el término Verwerfung -y sus variantes verwerfen, verworfen, verwarf- en tres sentidos distintos: en el caso del hombre de los lobos (Freud, 1918/1986a) especifica un modo de rechazo de la castración; en un escrito de los fundacionales de su psicopatología, en 1894, desarrolla una modalidad de la defensa vinculada a la psicosis (Freud, 1894/1986c); finalmente, hay un uso que se enmarca en una reflexión metapsicológica en torno de la estructura representacional del psiquismo inconsciente.

A esta multivocidad del término debe agregársele un cuarto modo de uso, presente en sus últimos escritos, donde se evidencia en lo absoluto técnico, es decir, sin remitirse a las acepciones referidas. En Construcciones en el análisis (1937/1986b), por ejemplo, en el marco de una reflexión concerniente a la verdad de las construcciones que el analista comunica a sus pacientes, comenta que "cada construcción la consideramos apenas una conjetura, que aguarda ser examinada, confirmada o desestimada" (Freud, 1937/1986b, p. 266) ${ }^{1}$; asimismo, en Esquema del psicoanálisis (1940/1986d) se refiere al tratamiento psicoanalítico, y comenta que este constituye una batalla entre el analista y las fuerzas que oponen resistencia en el paciente, y advierte

$\mathrm{Su}$ desenlace es indiferente: ya sea que el yo acepte tras nuevo examen una exigencia pulsional hasta entonces rechazada, o que vuelva a desestimarla \{verwerfen , esta vez de manera definitiva, en cualquiera de ambos casos queda eliminado un peligro duradero, ampliada la extensión del yo, y en lo sucesivo se torna innecesario un costoso gasto (Freud, 1940/1986d, p. 179). 
El empleo no técnico del término, como se aprecia en estas citas ubicadas en la parte final de su obra, conducen a la siguiente interrogación: ¿hay un concepto de Verwerfung en la obra de Freud? A continuación se exponen los tres sentidos con que Freud la utilizó.

\subsection{La Verwerfung de la castración}

El abordaje desplegado por Freud en el historial clínico del Hombre de los lobos (1918/1986a), le permite identificar un modo particular de rechazo de la castración al que denomina Verwerfung. En el escrito, lleva al lector al camino de la reconstrucción de la historia infantil de la neurosis de su paciente, $y$ en ese contexto relata un episodio en el que este contaba 4 años de vida. Dicho episodio cobra especial significación para el análisis desarrollado por Freud, porque de él se deducen los efectos que ha tenido en ese entonces el esclarecimiento de la diferencia sexual:

le arrimaron el discernimiento de la diferencia entre los sexos y del papel sexual de la mujer. Se comportó entonces como suelen hacerlo los niños a quienes se da un esclarecimiento indeseado -sexual o de otra clase-. Desestimó lo nuevo -en nuestro caso por motivos derivados de la angustia de castración- y se atuvo a lo antiguo ${ }^{2}$ (Freud, 1918/1986a, p. 73).

Lo antiguo constituía, para el paciente de Freud, la concepción anal del coito, derivada a su vez en lo que Freud había denominado teoría de la cloaca (1908/1986e), y que su paciente había configurado como una fantasía, a saber, la escena primaria del coito entre los padres.

Freud se encarga prontamente de establecer que este modo de proceder de lo inconsciente -desestimar lo nuevo y atenerse a lo antiguo-, se diferencia de lo que él mismo ha desarrollado bajo el rótulo de la represión: "Una represión $\{$ Verdrängung $\}$ es algo diverso de una desestimación \{Verwerfung\}" (Freud, 1918/1986a, p. 74). Este pasaje de la obra de Freud, en la medida en que plantea la diferencia entre la Verwerfung y la represión, tiene el valor de apuntalar la primera con el estatuto de concepto.

En el mismo texto, Freud realiza dos precisiones que permiten especificar las particularidades que hacen de la Verwerfung algo diverso que la represión. He aquí la primera:
Nos ha devenido notoria la inicial toma de posición de nuestro paciente frente al problema de la castración. La desestimó y se atuvo al punto de vista del comercio por el ano. Cuando dije que la desestimó, el significado más inmediato de esta expresión es que no quiso saber nada de ella siguiendo el sentido de la represión \{esfuerzo de desalojo $\}$. Con ello, en verdad, no se había pronunciado ningún juicio respecto de su existencia, ni siquiera podía seguir siéndolo en los años de su neurosis infantil. Después se encuentran buenas pruebas de que él había reconocido la castración como un hecho. Se había comportado también en este punto como era característico de su naturaleza, lo cual por otra parte nos dificulta muchísimo tanto la exposición como la empatía. Primero, se había revuelto y luego cedió, pero una reacción no había cancelado a la otra. Al final subsistieron en él, lado a lado, dos corrientes opuestas, una de las cuales abominaba de la castración, mientras que la otra estaba pronto a aceptarla y consolarse con la feminidad como sustituto. La tercera corriente, más antigua y profunda, que simplemente había desestimado la castración, con la cual no estaba todavía en cuestión el juicio acerca de su realidad objetiva, seguía siendo sin duda activable ${ }^{3}$ (Freud, 1918/1986a, p. 78).

De lo anterior, pueden extraerse una primera precisión, en términos de una definición de la Verwerfung: constituye un rechazo a saber de la castración -es decir, aparece como un modo específico de enfrentar la castración por la vía de la ignorancia-, que se configura como la ausencia del juicio acerca de su existencia, que por lo demás puede tener una incidencia localizada o parcial en lo inconsciente, pudiendo tener efectividad en coexistencia con otros modos de arreglo con la castración, como puede ser la represión.

Una segunda precisión surge en el mismo historial, a partir de la articulación entre una alucinación y un sueño: Freud comenta un episodio de la infancia de su paciente, en que se presenta la alucinación de haberse cortado accidentalmente un dedo. De esta, conjetura que "cayó en la época en que se decidió a reconocer la realidad objetiva de la castración, y acaso estuvo destinada a marcar precisamente ese paso" (Freud, 1918/1986a, p. 79). Si la interpretación freudiana, que se sostiene asimismo en el hecho de hacer equivaler el dedo al falo, es reconocida como una pieza del texto y ubicada en el contexto de lo que Freud viene desarrollando en 
el escrito, entonces se concluye que esa alucinación hace intervenir la castración que la Verwerfung ha dejado por fuera del saber inconsciente, es decir, el dedo cortado actuaría como un efecto de la amenaza de castración que no ha sido admitida en lo inconsciente. Justamente, más adelante, pone nuevamente en relación la Verwerfung y la angustia de castración, esta vez respecto del sueño de los lobos: "Del análisis del sueño angustioso inferimos que la represión subsiguió al conocimiento de la castración. Lo nuevo es desestimado ${ }^{4}$ porque su aceptación costaría el pene" (Freud, 1918/1986a, p. 100).

\subsection{La Verwerfung como defensa}

Un análisis integral de la obra freudiana conduce a revelar en la teoría de la defensa uno de los pilares de su pensamiento (Assoun, 2003). En efecto, se puede reconocer desde muy temprano en su obra el esfuerzo de conjeturar un aparato psíquico que le da un lugar preponderante a la defensa, constituyéndose en el tiempo como "el operador de la explicación metapsicológica" (Assoun, 2002, p. 49).

Ya en 1894 evidencia un primer desarrollo sobre un modelo defensivo en el aparato psíquico que le permite sostener la hipótesis de que el síntoma es una consecuencia de la defensa que ha intervenido en la representación inconciliable. Así, diferenciando el cuadro de las neuropsicosis de defensa, como neurosis adquiridas, es decir, sin tara hereditaria, plantea que en ellas sobreviene una inconciabilidad en el ámbito de las representaciones del psiquismo, que mueve al Yo a defenderse de ella, mediante el empleo de una defensa. Ubica, así, el mecanismo conversivo para la histeria, el divorcio entre representación y afecto, seguido por un falso enlace entre afecto y otra representación, para la neurosis obsesiva, y la Verwerfung para la confusión alucinatoria.

En todos los casos, advierte Freud, la defensa produce un olvido a medias: "ese «olvido» no se logró, sino que llevó a diversas reacciones patológicas que provocaron una histeria, o una representación obsesiva, o una psicosis alucinatoria" (Freud, 1894/1986c, p. 50). Y aunque aclara que distintas modalidades defensivas pueden presentarse simultáneamente en el mismo enfermo, identifica en la Verwerfung algo propio al campo de las psicosis:

...existe una modalidad defensiva mucho más enérgica y exitosa, que consiste en que el yo desestima \{verwerfen $\}$ la representación insoportable junto con su afecto y se comporta como si la representación nunca hubiera comparecido. Solo que en el momento en que se ha conseguido esto, la persona se encuentra en una psicosis que no admite otra clasificación que "confusión alucinatoria" (Freud, 1894/1986c, p. 59).

Se observa, así, una doble referencia respecto del mecanismo: por un lado, que como defensa interviene en la representación inconciliable y en su afecto -se verá más adelante cómo esto agrega ya algunas especificaciones que lo distinguen de otras modalidades defensivas-, por otro lado, que su consecuencia es el estallido de la psicosis. Se halla aquí el fundamento para pensar la proximidad de la Verwerfung como defensa, con lo que desarrolla en 1918 a propósito del Hombre de los lobos: aquí dice que se rechaza la representación y su afecto, allá, que no se quiere saber nada acerca de algo específico -la castración-.

Si se sigue la senda de la elaboración freudiana de las psicosis, se pueden encontrar referencias que amplían el sentido de lo que aquí se advierte:

la etiología común para el estallido de una psiconeurosis o de una psicosis sigue siendo la frustración, el no cumplimiento de uno de aquellos deseos de la infancia, eternamente indómitos, que tan profundas raíces tienen en nuestra organización comandada filogenéticamente. Esta frustración siempre es, en su ultimo fundamento, una frustración externa; en el caso individual, puede partir de aquella instancia interna (dentro del superyó) que ha asumido la subrogación del reclamo de la realidad. Ahora bien, el efecto patógeno depende de lo que haga el yo en semejante tensión conflictiva: si permanece fiel a su vasallaje hacia el mundo exterior y procura sujetar al ello, o si es avasallado por el ello y así se deja arrancar de la realidad (Freud, 1924/1984a, p. 157).

En ese sentido, si la Verwerfung interviene en la representación insoportable y su afecto, lo que produce es una huida de la realidad. En ese punto, se ubicaría la distinción entre neurosis y psicosis. Sin embargo, en un texto posterior, Freud corrige esta aproximación estructural, agregando una necesaria rectificación: 
Hace poco tiempo indiqué como uno de los rasgos diferenciales entre neurosis y psicosis que en la primera el yo, en vasallaje a la realidad, sofoca un fragmento del ello (vida pulsional), mientras que en la psicosis ese mismo yo, al servicio del ello, se retira de un fragmento de la realidad. Por lo tanto, lo decisivo para la neurosis sería la hiperpotencia del influjo objetivo, y para la psicosis, la hiperpotencia del ello. La pérdida de realidad \{objetividad $\}$ estaría dada de antemano en la psicosis; en cambio, se creería que la neurosis la evita (Freud, 1924/1984a, p. 193).

Así, Freud va diferenciando los efectos del mecanismo de la psicosis en relación con la realidad, trazando un paralelo con la neurosis. En ese sentido, con la corrección que propone a su propia teorización, establece que "la neurosis no desmiente la realidad, se limita a no querer saber nada de ella; la psicosis la desmiente y procura sustituirla"" (Freud, 1924/1984a, p. 195). Entonces, se tiene, por un lado, que el neurótico no desmiente (verleugnet) la realidad, pero al mismo tiempo que no quiere saber nada de ella. Esta expresión -no querer saber- es la misma que ha utilizado para referirse a la Verwerfung, aunque en esta ocasión aparece ligada a otro término, la desmentida o Verleugnung.

Entre 1894 y 1926, Freud introdujo modificaciones a la teoría de la defensa, como son distinguir defensa y represión, desarrollar el concepto de formación reactiva y repensar la defensa más allá de la estructura del Yo. En ese período, la Verwerfung desaparece como defensa, quedando solo como la modalidad propia de rechazo de la castración que ha sido descrita en el punto anterior.

\subsection{Verwerfung, Urteilsverwerfung $y$ Ausstoßung}

En La negación (1925), de soslayo a lo que se articula en la centralidad del escrito, Freud ensaya una teorización metapsicológica respecto del modo en que se articulan las percepciones de la realidad y las representaciones psíquicas. Freud intenta establecer los fundamentos que harían posible la operación de la negación, pero en ello acaba formulando su concepción acerca del examen o prueba de realidad. Respecto de esa vía, sostiene

Puesto que es tarea de la función intelectual del juicio afirmar o negar contenidos de pensamiento, las consideraciones anteriores nos han llevado al origen psicológico de esa función. Negar algo en el juicio quiere decir, en el fondo, "Eso es algo que yo preferiría reprimir". El juicio adverso \{Verurteilung es el sustituto intelectual de la represión, su "no" es una marca de ella, su certificado de origen (Freud, 1925/1984b, p. 254).

Aunque Freud no le ha dedicado mucho a lo que aquí enuncia, pueden hallarse referencias anteriores en su obra, más bien pasajes marginales antes que desarrollos que protagonicen sus textos. Así, en su escrito del chiste (1905/1986f), especula con que en el inconsciente

hace falta todo proceso comparable al "juzgar". En lugar de la desestimación por el juicio $\{$ Urteilsverwerfung , hallamos en lo inconsciente la represión \{Verdrängung, "esfuerzo de desalojo"\}. Acaso la represión pueda describirse correctamente como el estadio intermedio entre el reflejo de la defensa y el juicio adverso \{Verurteilung (Freud, 1905/1986f, p. 167).

De lo que se desprende que en ese punto de su teorización no está en condiciones de pensar el juicio de atribución. Por ello aquí aparece como un referente hipotético que permite pensar la represión como un modo de la defensa que queda a medias en el intento por desestimar la representación que introduce el displacer.

Más tarde, en 1911, se observa ya un giro de lo anterior, allí señala que

En lugar de la represión, que excluía de la investidura a algunas representaciones emergentes por generadoras de displacer, surgió el fallo imparcial que decidiría si una representación determinada era verdadera $\mathrm{o}$ falsa, vale decir, si estaba o no en consonancia con la realidad; y lo hacía por comparación con las huellas mnémicas de la realidad (Freud, 1911/1986g, pp. 225-226).

Si bien el término empleado aquí es Urteilsfällung, y no Urteilsverwerfung, como en la cita anterior, ni tampoco Veruteilung, como en La negación, de 1925, se puede evidenciar la proximidad semántica entre los dichos.

En 1915, vuelve a retomar este desarrollo: 
Si se tratase del efecto de un estímulo exterior, es evidente que la huida sería el medio más apropiado. En el caso de la pulsión, de nada vale la huida, pues el yo no puede escapar de sí mismo. Más tarde, en algún momento, se encontrará en la desestimación por el juicio (juicio adverso) un buen recurso contra la moción pulsional. Una etapa previa al juicio adverso, una cosa intermedia entre la huida y el juicio adverso, es la represión, cuyo concepto no podía establecerse en el período anterior a los estudios psicoanalíticos ${ }^{6}$ (Freud, 1915/1984c, p. 141).

Resulta significativo reconocer en estas palabras que Freud hace equivaler Urteilsverwerfung a Verurteilung, y en esa misma línea, que vuelve a poner a la represión entre dos referentes, esta vez entre el juicio adverso y la huida. Es decir, en este texto, el juicio adverso ya no queda definido como un imposible, pues la huida queda ubicada de tal modo. El juicio adverso se vuelve una posibilidad que inclusive Freud reconoce como pudiendo presentarse con posteriorioridad a la represión.

Se aprecia, en efecto, que si bien es cierto estos desarrollos se despliegan en diversos textos, puede atribuírsele a ellos el estatuto de una prueba de que en Freud se ha venido fraguando una reflexión que recién se plasma en La negación (1925).

Si primero pensó en la desestimación del juicio como una referencia intelectual imposible, y luego como una posibilidad temporalmente posterior a la represión, en 1925 presenta un análisis de su proceso. Se refiere entonces de un modo más general a la función del juicio, y precisa que

tiene, en lo esencial, dos decisiones que adoptar. Debe atribuir o desatribuir una propiedad a una cosa, y debe admitir o impugnar la existencia de una representación en la realidad. La propiedad sobre la cual se debe decidir pudo haber sido originalmente buena o mala, útil o dañina. Expresado en lenguaje de las mociones pulsionales orales, las más antiguas: "Quiero comer o quiero escupir esto". Y en una traducción más amplia: "Quiero introducir esto en mí o quiero excluir esto de mí” (Freud, 1925/1984b, p. 254).

Así, para Freud el juicio de atribución opera aceptando e incorporando lo bueno y expulsando de sí lo que rechaza, es decir, orientado por el principio de placer.
Si se toma en consideración que, para Freud, "[...] todas las representaciones provienen de percepciones, son repeticiones de estas" (Freud, 1925/1984b, 255), entonces el psiquismo inconsciente hace intervenir el juicio para afirmar o rechazar la existencia de aquello que una vez percibido deviene una representación. Esto asimismo permite entender por qué señala Freud que el juicio puede atribuir la existencia de una representación en la realidad, pues

La otra de las decisiones de la función del juicio, la que recae sobre la existencia real de una cosa del mundo representada, es un interés del yo-realidad definitivo, que se desarrolla desde el yo-placer inicial (examen de realidad). Ahora no se trata de su algo percibido (una cosa del mundo) debe ser acogido o no en el interior del yo, sino de si algo presente como representación dentro del yo puede ser reencontrado también en la percepción (realidad) (Freud, 1925/1984b, p. 255).

La teorización freudiana hace articular una dialéctica entre la percepción y la representación, en la que la primera actúa como antecesor de la segunda, pero solo para ver después cómo la representación en el yo dispone al reencuentro con algo en la vía de la percepción. Esto conduce a la interrogación por el modo en que se constituyen asimismo las representaciones. En efecto, las representaciones psíquicas han de atravesar por un proceso que ha de ser temporal y lógicamente anterior a la función del juicio y a la defensa, es decir, aunque sea de Perogrullo, que para que la represión u otro modo de la defensa intervenga en una representación del aparato psíquico, esa representación ha debido inscribirse en lo inconsciente, y para que una representación sea desestimada, esta debió inscribirse previamente en el psiquismo. Freud lo resume del siguiente modo:

El juzgar es ulterior al desarrollo, acorde a fines de la inclusión \{Einbeziehung $\}$ dentro del yo o a la expulsión de él, que originariamente se rigieron por el principio de placer. Su polaridad parece corresponder a la oposición de los dos grupos pulsionales que hemos supuesto. La afirmación -como sustituto de la uniónpertenece a Eros, y la negación -sucesora de la expulsión-, a la pulsión de destrucción ${ }^{7}$ (Freud, 1925/1984b, p. 256). 
Aunque en este escrito Freud no emplee el término Verwerfung, sí puede constatarse que se ha servido de uno de significado próximo, Ausstoßung, en un sentido que es del todo consistente.

Para concluir este punto, es importante referirse a algunos antecedentes que, aunque puedan parecer anecdóticos, no dejan de ser llamativos: $L a$ negación (1925) muestra una notoria influencia del filósofo Franz Brentano, a quien Freud tuvo de profesor en la Facultad de Medicina en la Universidad de Viena. La influencia del filósofo respecto del psiquismo representacional, en la formulación del aparato psíquico freudiano es archiconocida. Pero este hecho redobla su valor al constatar la cercanía que expresan algunos planteamientos freudianos del texto comentado, con la Psychologie vom empirischen Standpunkt de Brentano, de 1874: "En Brentano se dibuja, al igual que en Freud, una serie que incluye lo afectivo y lo judicativo; de carácter positivo, como afirmación [Annehmen]-bueno-placer, y de carácter negativo, como negación [Verwerfen]malo-displacer" (Kripper, 2011, p. 162).

Esto resulta particularmente relevante debido a que Lacan, al comentar el escrito de Freud, hace equivaler Ausstoßung y Verwerfung. En efecto, resulta del todo plausible que Lacan haya conocido el texto de Brentano y haya sabido de la proximidad en esas líneas.

\section{EL FORCLUSIF DE DAMOURETTE Y PICHON Y SU RELACIÓN CON LA PSICOPATOLOGÍA DE LAFORGUE}

A diferencia de otras notables intervenciones en que Lacan ha recogido un término de otro autor, para hacer una lectura que deriva del comentario a la invención, en el caso de la forclusión se observa un silencio respecto de la referencia de donde ha tomado el término. El escrito, Sur la signification psychologique de la négation en français, de Damourette y Pichon, fue publicado en el Journal de psychologie normal et pathologique en 1928, y desarrolla una reflexión en torno del fenómeno de la negación en la gramática francesa, y permite a los autores identificar una modalidad de la negación a la que denominan forclusif.

Resulta especialmente llamativo que Lacan no cite el texto a propósito de su forclusión, mas sí lo haga en su comentario respecto de La negación de Freud (1925), en el contexto de su seminario de 1958 (Lacan, 1958/2014), es decir, casi tres años después de haber presentado a la forclusión. Esta omisión contrasta con las referencias de Lacan a Pichon: según consta en el Index référentiel de Henry Krutzen (2009), Lacan se refiere a Pichon en 14 ocasiones en el curso de su seminario: asimismo, en los Escritos, es nombrado en 6 ocasiones (Arrivé, 2004).

Estas referencias están más próximas al elogio que a la crítica: en efecto, de Pichon ha llegado a decir que es "autor de una obra genial en gramática" (Lacan, 1955/2002, p. 347) y lo ha puesto delante de todo el grupo de psicoanalistas de su generación. Arrivé (2004) explica el respeto y cordialidad de Lacan con Pichon como agradecimiento hacia quien fuese presidente de la Societé Psychanalytique de Paris en 1934, momento en que Lacan ha sido admitido como miembro titular.

Así como ha demostrado Roudinesco (1994), la relación de respeto y cordialidad entre Lacan y Pichon empieza a verse interrumpida, o a lo menos amenazada, a partir de la publicación de La familia, en 1938. A partir de ella, se puede identificar el distanciamiento en cuestiones ideológicas entre ellos, lo que se vio plasmado en ese escrito y en la respuesta que Pichon le dedicó en 1939.

Pichon (1939), que era miembro de la Action française, una agrupación nacionalista y monárquica, se decidió a publicar sus observaciones pertinentes a "La familia", en la Revue française de Psychanalyse. Junto con dedicar el texto a Lacan, plasmó una crítica con ironía, en la que reprochó la filiación de Lacan a autores alemanes como Hegel y Marx.

En la misma línea puede ubicarse una carta de Pichon dirigida a Henri Ey, donde el primero expresa su decepción con el "amoralismo un poco tontorrón" (Roudinesco, 1994, p. 224) de Lacan, además del enojo que le ha provocado que Lacan deslice una crítica a su teoría de la oblatividad, sin mencionarlo. En su crítica, Pichon reprocha el manejo que Lacan tiene de sus fuentes, en particular por no referirse a Laforgue al hablar del destete y sus efectos.

Según ha observado Baños (2016), mediante su crítica, Pichon parecería desconocer que el texto redactado por Lacan estaba destinado originalmente a ser publicado en la Encyclopédie française, donde ningún autor referenciaba sus fuentes. De allí que la rudeza con que Pichon trata a Lacan pueda ser leída desde otros antecedentes. En ese sentido, parece guardar relación con el hecho de que su comentario se publica justamente en el mismo número de la Revue Française de Psychanalyse en 
que se anuncia el nombramiento de Lacan como miembro titular de la Societé Psychanalytique de Paris. En efecto, Lacan esperaba ya hace un tiempo su nombramiento, pero la opinión que suscitaba en Rudolph Löwenstein, su analista didacta, había constituido el principal obstáculo para ello. No fue sin la influencia de Pichon que Lacan pudo ser nombrado finalmente, con lo que Baños (2016) advierte tras su ofensiva, una "oportunidad para disciplinar a su protegido" (p. 23). A esas alturas, el joven Lacan ya había dado muestras de un carácter intelectual de poca obediencia por las jerarquías académicas e institucionales.

\subsection{La gramática de Damourette y Pichon}

En el escrito se analiza la función de la negación en la lengua francesa, y propone reconstruir los taxemas que la constituyen, es decir, el modo en que las dos piezas que la componen habitualmente, a saber, el ne y el pas -pero también el rien, jamais, aucun y personne-, pasan a constituirla. El resultado de su aproximación les permite afirmar que en la lengua y el pensamiento francés no es posible la negación en propiedad, y que sus formas develan otros usos ${ }^{8}$.

Damourette y Pichon (1930/1968) afirman que, en el francés de su época, es decir, el de las primeras décadas del siglo XX, ya es común hallar enunciados en que la negación no se constituye por la presencia conjunta de ambos taxemas. En ese contexto, advierten que cuando ella aparece marcada puramente por el $n e$, resulta más suave que aquella en que aparece puramente la segunda partícula. En efecto, si mediante el uso del pas, rien, etc., se establece una negación enfatizada, con los usos puros del ne, se construyen oraciones que no representan propiamente una negación, ni genuinamente una afirmación.

A partir de esto, los autores proponen el término de discordantiel para aquellos casos en que mediante el ne se produce una discordancia entre lo que el sujeto dice y el sentido de lo que dice ${ }^{9}$, cuestión que descubren es de un uso más habitual en enunciados que expresan miedo, precaución o impedimento.

A la segunda pieza de la negación, la denominan forclusif: se trata de enunciados constituidos por palabras como nada, nunca, ninguno, nadie, más, a penas, etc., y se aplica a hechos que el hablante no considera parte de la realidad ${ }^{10}$. Un ejemplo comentado por Lacan es la expresión Il n'y a personne ici (no hay nadie aquí), de la que dice “está excluido que aquí haya alguien” (1958/2014, p. 97). Pichon y Damourette sostienen que se trata de expresiones que expulsan una posibilidad para el hablante.

Las páginas finales del escrito introducen un giro que permite explicar por qué han elegido una revista de psicología y psicopatología como espacio para la difusión de su obra: apoyados en la elucidación del forclusif, sostienen la proximidad entre este y un particular mecanismo psicopatológico desarrollado por Laforgue y Pichon. Así, advierten que el arrepentimiento, en tanto deseo de que algo del pasado no hubiera sucedido jamás, halla en el forclusif una realización en el lenguaje. Para Damourette y Pichon, esta formación en la lengua francesa traduce una normal escotomización que en la teoría de Laforgue se observa como exageración patológica.

\subsection{La schizonoïa y la esctotomización de Laforgue}

Mediante la publicación de "Verdrängung und Skotomisation", en la International Zeitschrift für Psychoanalyse, en 1926 y "Schizophrénie et schizonoïa", en la Revue française de psychanalyse, en 1927, René Laforgue (1894-1962) dio a conocer la teoría del mecanismo de la escotomización y su relación con la esquizofrenia y algunas neurosis graves. El fenómeno, descrito anteriormente por Hyppolite Bernheim (1840-1919) como efecto posthipnótico, fue circunscrito por Laforgue a la relación establecida entre el niño y su madre. En el ámbito de esa relación fundamental, este psicoanalista francés ubica, como causa de ciertos desarrollos patológicos de la personalidad, una reacción negativa del niño a la frustración de la madre.

En 1927, luego de declararse cercano a los planteamientos de Freud concernientes a la libido y la sexualidad infantil, Laforgue se enfila hacia un análisis de las situaciones tempranas del bebé con la madre. En ese contexto, afirma que la aproximación a los conflictos psíquicos lo conducen a los efectos del destete en el desarrollo emocional. En efecto, para Laforgue, el destete constituye el puntapié inicial de un devenir que lleva al niño a separarse de la madre, para más tarde desarrollar su personalidad social.

En ciertos casos, no obstante, para Laforgue (1927) el proceso fracasa: el niño no logra tolerar la 
separación-destete y él mismo substituye a la madre que ha perdido en la realidad. A este proceso, que ubica en la germinación de las psicosis y ciertas neurosis obsesivas, lo denomina schizonoïa, y a su mecanismo subyacente, escotomización.

Para evitarse la frustración ocasionada por la ausencia de la madre, el niño la sustituye en su imaginación, y con ello debilita el vínculo con su madre en la realidad, y, en consecuencia, con la realidad toda. En ese sentido, Laforgue (1926) advierte que la escotomización revierte el displacer introducido en la experiencia, expulsando algo de la realidad que luego será sustituido por el Yo del individuo ${ }^{11}$, $y$, en consecuencia, si la represión defiende al sujeto de una moción de deseo, la escotomización, dice Laforgue (1927), es su realización, es decir, aquello que conduce a la satisfacción de un deseo ${ }^{12}$.

Este concepto tuvo cierta recepción en el ambiente psicoanalítico, llegando a ser citado por Freud (1926/1986h) a propósito de ciertos fenómenos histéricos que él mismo había puesto en otros momentos en relación con la alucinación negativa de Bernheim. No obstante, un año más tarde, Freud (1927/1986i) introdujo su Verleugnung -traducida como desmentida o renegación-, como concepto metapsicólogico que daría explicación al mismo fenómeno. En efecto, Freud advierte la similitud entre su Verleugnung y la escotomización de Laforgue, mas prontamente se encarga de advertir que este último no es un concepto psicoanalítico, y que se relaciona con la dementia praecox y no con las neurosis.

Nótese hasta aquí, que, si bien el forclusif aparece como un término que antecede la forclusión de Lacan, y que, en definitiva, algo de su significado parece deslizarse en esa sustitución terminológica, no obstante, desde sus propios autores aparece vinculada, en última instancia, a la Verleugnung y no a la Verwerfung de Freud.

\section{VERWERFUNG Y FORCLUSIÓN EN LACAN: 1954-1959}

Las primeras aproximaciones de Lacan a la Verwerfung apuntan, como ya ha sido dicho, al problema de su traducción. Tomando el pasaje del historial del Hombre de los lobos en que Freud presenta la Verwerfung como un rechazo al saber de la diferencia sexual, Lacan critica la traducción que se ha hecho del término de Freud como "un juicio que rechaza y elige" (Lacan, 1953/1981, pp. 74-75), y en un intercambio con Jean Hyppolite, concuerda que mejor habría sido traducirla simplemente por "rechazo" (p. 75). En otros pasajes del mismo seminario, se inclinará por reconocer en la Verwerfung un rechazo que implicaría, a fin de cuentas, una ausencia de la Bejahung, es decir, una falta a nivel de la simbolización, preferentemente ligada al "sentido del plano genital" (p. 110), que definirá como "rechazo originario" (p. 412).

En virtud de su disconformidad con la traducción, propondrá en la clase del 4 de julio de 1956, el término de forclusión. Pero debido a que desde entonces utiliza alternadamente el término Verwerfung y el de forclusión, puede plantearse que, desde su perspectiva, ambos le resultan equivalentes, a pesar de que, con el segundo, ha introducido algunas modificaciones en sintonía con su teoría del significante.

En 1955, a propósito del comentario que ha hecho Hyppolite sobre La negación (1925), Lacan sostiene

Lo que destaca claramente su análisis de este texto fulgurante, es que en lo inconsciente, todo no está tan solo reprimido, es decir desconocido por el sujeto luego de haber sido verbalizado, sino que hay que admitir, detrás del proceso de verbalización, una Bejahung primordial, una admisión en el sentido de lo simbólico, que puede a la vez faltar (Lacan, 1955/1984, p. 23).

Esta Bejahung primordial, Lacan la propone como el "juicio de atribución, que Freud establece como precedente necesario de toda aplicación posible de la Verneinung" (Lacan, 1959/2003b, p. 539), es decir, como una admisión o afirmación del significante, que intervendría en un nivel radicalmente primordial para el sujeto. En ese sentido, para Lacan, habrá Bejahung o Verwerfung. En caso de haber la primera, se producirá "simbolización primitiva" (1955/1984, p. 119); la Verwerfung queda definida, así, como "ausencia de esa Bejahung" (Lacan, 1959/2003b, p. 539), lo que, dicho en relación con los términos introducidos por Lacan en su lectura de Freud, es decir, a partir de la formulación del inconsciente estructurado como un lenguaje, quiere decir que

...será pues considerada por nosotros como preclusión del significante. En el punto donde, ya veremos cómo, es llamado el Nombre-delPadre, pues puede responder en el Otro un 
puro y simple agujero, el cual por carencia del efecto metafórico provocará un agujero correspondiente en el lugar de la significación fálica (1959/2003b, p. 540).

La forclusión del Nombre-del-Padre, representa la no inscripción en lo simbólico del significante que haría posible significar el deseo de la madre, es decir, producir la significación de su castración, y de su falta, en la metáfora paterna. Que Lacan diga que en el Otro podría responder solo el agujero, señala la consecuencia de la forclusión del significante del Nombre-del-Padre, como ruptura de la estructura significante en cuanto tejido o encadenamiento simbólico. Pero que Lacan proponga un nexo tan acabado entre la psicosis y la forclusión del Nombre del Padre, no excluye que él también haya afirmado que a esta condición estructural deben advenir otras para producir el desencadenamiento psicótico:

Para que la psicosis se desencadene, es necesario que el Nombre-del-Padre, verworfen, precluido, es decir sin haber llegado nunca al lugar del Otro, sea llamado allí en posición simbólica al sujeto. Es la falta del Nombredel-Padre en ese lugar la que, por el agujero que abre en el significado, inicia la cascada de los retoques del significante de donde procede el desastre creciente de lo imaginario, hasta que se alcance el nivel en que el significante y significado se estabilizan en la metáfora delirante (1959/2003b, pp. 558-559).

En otros términos, su planteo es que la forclusión del Nombre-del-Padre constituye un agujero en lo simbólico que, en la medida en que no sea convocado, podrá mantenerse en cierta indemnidad para el sujeto. Pero, además, que el desencadenamiento psicótico se produce en conformidad con un llamado al Otro que hace reproducir ese agujero simbólico a nivel de lo imaginario, es decir, a nivel de la significación, donde el delirio produce un anudamiento capaz de construir una estabilización sintomática para el sujeto.

¿Pero qué quiere decir que el significante no inscrito en lo simbólico pueda ser convocado o llamado en el lugar del Otro? Pues bien, para Lacan no hay dudas,

por ninguna otra cosa sino por un padre real, no en absoluto necesariamente por el padre del sujeto, por Un-padre. [...] basta para ello que ese Un-padre se sitúe en posición tercera en alguna relación que tenga por base la pareja imaginaria $a$ - $a$ ', es decir yo-objeto o ideal-realidad (Lacan, 1959/2003b, p. 559).

Podría decirse que se trata del punto en que el Padre real hace surgir, en el llamado de la cadena significante, al Nombre del Padre, como significante que representa a la ley, es decir a la castración. Si Freud ha sostenido que la castración no admitida por su paciente, se le ha presentado en la alucinación del dedo cortado, Lacan señala que "todo lo rehusado en lo simbólico, en el sentido de la Verwerfung, reaparece en lo real" (Lacan, $1955 / 1984$, p. 24).

En este sentido, se observa que, para Lacan, la forclusión del Nombre-del-Padre ocasiona un retorno que, según dependa el caso, podrá constatarse en sus efectos alucinatorios, pero también en el modo en que lo real irrumpe desajustando la trama simbólico-imaginaria en que se afirma la realidad. Así, por un aparte Lacan señala que en el desencadenamiento psicótico

lo que está verworfen, o rechazado de lo simbólico, reaparece en lo real. Ese real del que se trata es la alucinación, es decir, el Otro en tanto que habla. Eso sigue hablando en el Otro, pero aquí adquiere la forma de lo real (Lacan, 1957/1999, p. 491).

\section{VERWERFUNG Y FORCLUSIÓN: 1960-1976}

Son dos los hechos que es posible destacar como parte de una segunda elaboración de la forclusión en Lacan: en primer lugar, que, si en el origen aparece estrictamente ligada a su elaboración de las psicosis, desde 1960 en adelante, esta relación deja de configurar el significado fundamental del concepto. En este sentido, la afirmación de Furman (2017), en cuanto establece que la forclusión constituye "un mecanismo específico y particular de la psicosis" (p. 457), está equivocada. Tardíamente, en la clase del 16 de marzo de 1976, se refiere a la orientación por real, encargándose de aclarar de entrada que dicha orientación no es un sentido, que dicha orientación "forcluye el sentido" (1975/2006, p. 119), y entonces advierte que la noche anterior le han preguntado por la existencia de otras forclusiones, que no fuesen la del Nombre-del-Padre. Ante ello responde: "Es muy cierto que la forclusión tiene algo más radical. El Nombre del Padre, es, a fin de cuentas, algo leve" (Lacan, 1975/2006, p. 119). 
Las otras forclusiones, aludidas aquí, emergen en la enseñanza de Lacan, en principio, a partir del modo en que se aproxima a lo que denomina el discurso de la ciencia. En ese contexto, pueden ubicarse distintas elaboraciones: la primera en 1960, donde afirma que la ciencia hace una Verwerfung de la Cosa (1959/1988), más tarde señala que hace una Verwerfung de la verdad como causa (1966/2003a) y un año más tarde indica que en ella hay una Verwerfung del ser (1967). En 1972, a propósito del discurso capitalista, sostiene que este hace una Verwerfung de la castración.

¿No sería apropiado, entonces, suponer que, en rigor, Lacan ha remitido su forclusión al ámbito de la psicosis, prefiriendo el uso del término freudiano para sus desarrollos pertinentes a la ciencia y el discurso capitalista, entre otros? La aclaración hecha por Lacan en 1976, referida recientemente, desacredita esta lectura, y de paso conduce al segundo hecho que resalta dentro del segundo período de elaboración de la forclusión: Lacan insiste en tal medida en el empleo del término alemán Verwerfung, después de introducir su forclusión, que, en efecto, en su seminario parece preferirlo por sobre ella ${ }^{13}$, de donde solo cabe concluir que, para Lacan, ambos términos son equivalentes.

Finalmente, siguiendo a Harari (1995), se puede establecer un nexo entre la forclusión y el modo en que Lacan se aproxima a algunos agujeros que insiste en sostener en su obra. Se trata de lo que no hay a nivel de lo simbólico, no como falta o carencia, en el sentido patológico, como se derivaría de la noción de forclusión del Nombre-del-Padre, sino como estructura propia del orden simbólico. Lacan se ha referido a dichos agujeros a partir de ciertos aforismos, a saber: no hay relación sexual, LA mujer no existe, no hay Otro del Otro, o no hay metalenguaje.

En efecto, si la forclusión puede ser más radical que aquello que se presenta como consecuencia de la ausencia de la metáfora paterna, ello parece guardar relación con cierta propiedad de la estructura del simbolismo, en términos de su incompletud.

\section{CONCLUSIONES}

La originalidad de Lacan en cuanto a la elaboración de la forclusión, jamás ha estado en cuestión. Lo desarrollado en este escrito permite evidenciar, en primer término, que si en cierto sentido para Lacan su concepto es equivalente a la Verwerfung de Freud, no puede obviarse, no obstante, que dicho concepto no ha tenido un desarrollo consistente en la obra de Freud, y en ese sentido, el primer mérito de Lacan ha sido rescatarlo en su valor para el entendimiento del fenómeno alucinatorio.

Por consiguiente, las piezas de la Verwerfung en que se apoya Lacan pueden reducirse a una ausencia de la Bejahung, o, en términos de Lacan, a la no inscripción de un significante. En ese sentido, puede constatarse la fidelidad de Lacan con el texto de Freud, y el esfuerzo por llevar su lectura más allá de este, explotando su uso para su teoría de la ciencia.

Hay, no obstante, en algunos empleos del concepto, un corrimiento de aquella delimitación en torno de la Bejahung. En efecto, ¿en qué medida la Verwerfung de la Cosa, del Ser y de la verdad como causa pueden ser circunscritas puramente a algo del orden de lo simbólico?

En este punto, parece conveniente revisar la solución propuesta por Eidelsztein, para quien la forclusión "es una forma de plantear que algo es suprimido de tal manera que no puede retornar en el mismo campo del que fue excluido" (2008, p. 14).

Esta definición tiene el mérito de no restringir la forclusión al registro de lo simbólico, aunque tampoco aclare los términos en que algo de cualquiera de los otros registros pudiese resultar forcluido, y en ese sentido, es lo suficientemente amplia como para dar cabida a las Verwerfung de la ciencia. Por cierto, resultaría incompatible con aquella lectura que permite hacer coincidir la forclusión con las derivaciones de la incompletud de lo simbólico: no podría afirmarse que la relación sexual, el Otro del Otro o la Mujer, han sido suprimidos. Su inexistencia o ausencia, es una cuestión de estructura.

Puede reconocerse, a su vez, que, en estos usos de la forclusión, el problema de su retorno quedaría menos explicitado, pues si para el caso de la alucinación lo forcluido en lo simbólico retorna en lo real (Lacan, 1955/1984), para las eventuales forclusiones en lo imaginario y en lo real, Lacan no ha precisado fórmulas para su retorno.

Puede apreciarse, a partir de estas discusiones, en qué medida también la forclusión de Lacan se aparta de la Verwerfung de Freud, para tener su propio desarrollo. En ese sentido, más allá de la equivalencia en el uso que les da Lacan, ambas no son, por esta razón, sinónimas. 
Finalmente, es admisible referirse a por qué Lacan no cita a Pichon. Acerca de esto, se pone en relieve algo que ha advertido J. C. Maleval (2002) y que el recorrido desarrollado en este trabajo permite sustentar: que debido al desarrollo del forclusif de Pichon y de la forclusión de Lacan, debe reconocerse que Lacan no les debe nada a Damourette y Pichon. En efecto, el forclusif, vía la escotomización de Laforgue, estaría más bien emparentada con la Verleugnung de Freud, es decir, con la desmentida, y no con la Verwerfung.
Lacan pudo mencionar en su seminario, si no en sus escritos, el texto de Damourette y Pichon para introducir su forclusión, pero no lo hizo. ¿Cuánto de esto obedece a algo de la trama desarrollada básicamente por Pichon en 1939? No es posible precisarlo, pero cuesta trabajo suponer que una y otra cosa no estén relacionadas. Tal vez, como hipótesis, pueda pensarse en su gesto de no citarlo, una forma sintomática que pone en escena lo que pervive de dicha trama, casi quince años después. 


\section{REFERENCIAS}

Arrive, M. (2004). Lenguaje y psicoanálisis, lingüística e inconsciente. Freud, Saussure, Pichon, Lacan. México: Siglo Veintiuno Editores.

Assoun, P. (2002). La metapsicología. México: Siglo Veintiuno Editores.

Assoun, P. (2003). El freudismo. Buenos Aires: Siglo Veintiuno Editores.

Baños, J. (2016). Guiraud, Loewenstein, Pichon. Jacques Lacan según el dictamen de sus primeros jueces. Revista Nácate, agosto. Disponible en: http://www.revistanacate.com/ wp-content/uploads/2016/08/Guiraud-Loewenstein-Pichon-J.Ba\%C3\%B1os.pdf

Damourette, J. y Pichon, E. (1968). De mots a la pensé. Essai de grammaire de la langue française 1911-1927. Paris: Éditions d'artrey (Texto originalmente publicado en 1930).

Eidelsztein. A. (2008). Las estructuras clínicas a partir de Lacan (vol. 1). (2a ed.). Buenos Aires: Editorial Letra viva.

Freud, S. (1946). Die Verdrängung. Gesammelte Werke (vol. 10, pp. 247-261). Londres: Imago Publishing Co. (Texto originalmente publicado en 1915).

Freud, S. (1948). Die Verneinung. Gesammelte Werke (vol. 14, pp. 9-15). Londres: Imago Publishing Co. (Texto originalmente publicado en 1925).

Freud, S. (1961). Konstruktionen in der Analyse. Gesammelte Werke (vol. 16, pp. 41-56) (2 edición). Frankfurt: S. Fischer Verlag. (Texto originalmente publicado en 1937).

Freud, S. (1966). Aus der Geschichte einer infantilen Neurose. Gesammelte Werke (vol. 12, pp. 27-157) ( $3^{\text {a }}$ edición). Frankfurt: S. Fischer Verlag. (Texto originalmente publicado en 1918).

Freud, S. (1967). Der Realitätsverlust bei Neurose und Psychose.

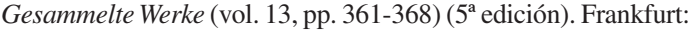
S. Fischer Verlag. (Texto originalmente publicado en 1924).

Freud, S. (1984a). La pérdida de la realidad en las neurosis y psicosis. En J. Strachey (Ed.) y J. J. L. Etcheverry y L. Wolfson (Trads.) Sigmund Freud Obras completas (vol. 19, pp. 189-197). Buenos Aires: Amorrortu Editores. (Trabajo originalmente publicado en 1924).

Freud, S. (1984b). La negación. En J. Strachey (Ed.) y J. L. Etcheverry y L. Wolfson (Trads.) Sigmund Freud Obras completas (vol. 19, pp. 249-257). Buenos Aires: Amorrortu Editores. (Trabajo originalmente publicado en 1925).

Freud, S. (1984c). La represión. En J. Syrachey (Ed.) y J. L. Etchevery y L. Wolfson (Trads.) Sigmund Freud Obras completas (vol. 14, pp. 135-152). Buenos Aires: Amorrortu Editores (Trabajo originalmente publicado en 1915).

Freud, S. (1986a). De la historia de una neurosis infantil. En J. Strachey (Ed.) y J. L. Etcheverry y L. Wolfson (Trads.) Sigmund Freud Obras completas (vol. 17, pp. 1-112). Buenos Aires: Amorrortu Editores (Trabajo originalmente publicado en 1918).

Freud, S. (1986b). Construcciones en el análisis. En J. Strachey (Ed.) y J. L. Etcheverry y L. Wolfson (Trads.) Sigmund Freud Obras completas (vol. 23, pp. 255-270). Buenos Aires: Amorrortu Editores (Trabajo originalmente publicado en 1937).
Freud, S. (1986c). Las neuropsicosis de defensa (Ensayo de una teoría psicológica de la histeria adquirida, de muchas fobias y representaciones obsesivas, y de ciertas psicosis alucinatorias). En J. Strachey (Ed.) y J. L. Etcheverry y L. Wolfson (Trads.) Sigmund Freud Obras completas (vol. 3, pp. 41-61). Buenos Aires: Amorrortu Editores (Trabajo originalmente publicado en 1894).

Freud, S. (1986d). Esquema del psicoanálisis. En J. Strachey (Ed.) y J. L. Etcheverry y L. Wolfson (Trads.) Sigmund Freud Obras completas (vol. 23, pp. 133-209). Buenos Aires: Amorrortu Editores (Trabajo originalmente publicado en 1940).

Freud, S. (1986e). Sobre las teorías sexuales infantiles. En J. Strachey (Ed.) y J. L. Etcheverry y L. Wolfson (Trads.) Sigmund Freud Obras Completas (vol. 9, pp. 183-201). Buenos Aires: Amorrortu Editores (Trabajo originalmente publicado en 1908).

Freud, S. (1986f). El chiste su relación con lo inconsciente. En J. Strachey (Ed.) y J. L. Etcheverry y L. Wolfson (Trads.) Sigmund Freud Obras completas (vol. 8, pp. 1-247). Buenos Aires: Amorrotu editores (Trabajo originalmente publicado en 1905).

Freud, S. (1986g). Formulaciones sobre los dos principios del acaecer psíquico. En J. Strachey (Ed.) y J. L. Etcheverry y L. Wolfosn (Trads.) Sigmund Freud Obras completas (vol. 12, pp. 217-231). Buenos Aires: Amorrortu Editores (Trabajo originalmente publicado en 1911).

Freud, S. (1986h). Inhibición, síntoma y angustia. En J. Strachey y J. L. Etcheverry y L. Wolfson (Trads.) Sigmund Freud Obras completas (vol. 20, pp. 71-164). Buenos Aires: Amorrortu Editores (Trabajo originalmente publicado en 1926).

Freud, S. (1986i). Fetichismo. En J. Strachey (Ed.) y J. L. Etcheverry y L. Wolfson (Trads.) Sigmund Freud Obras completas (vol. 21, pp. 141-152). Buenos Aires: Amorrortu Editores (Trabajo originalmente publicado en 1927).

Furman, M. (2017). El concepto de forclusión. En Chorne, M. y Dessal, G. (Eds.) Jacques Lacan. El psicoanálisis y su aporte a la cultura contemporánea (pp. 457-461). Madrid: Fondo de Cultura Económica

Harari, R. (1995). ¿Cómo se llama James Joyce? A partir de «El Sinthoma», de Lacan. Buenos Aires: Amorrortu Editores.

Kripper, A. (2011). La negación: los antecedentes brentanianos en el texto de Freud. Revista de epistemología y ciencias humanas, $\mathrm{N}^{\mathrm{o}} 3$, pp. 156-166.

Lacan, J. (1967). La lógica del fantasma. Seminario inédito. Lacan, J. (1971). El saber del psicoanalista. Seminario inédito. Lacan, J. (1981). El seminario de Jacques Lacan. Libro 1. Los escritos técnicos de Freud. Buenos Aires: Ed. Paidós (Seminario impartido en 1953).

Lacan, J. (1984). El seminario de Jacques Lacan. Libro 3. Las psicosis. Buenos Aires: Ed. Paidós (Seminario impartido en 1955).

Lacan, J. (1988). El seminario de Jacques Lacan. Libro 7. La ética del psicoanálisis. Buenos Aires: Ed. Paidós (Seminario impartido en 1959). 
Lacan, J. (1999). El seminario de Jacques Lacan. Libro 5. Las formaciones del inconsciente. Buenos Aires: Ed. Paidós (Seminario impartido en 1957).

Lacan, J. (2002). Variantes de la cura-tipo. En Escritos 1 (pp. 311-348). Buenos Aires: Siglo Veintiuno Editores (Trabajo originalmente publicado en 1955).

Lacan, J. (2003a). La ciencia y la verdad. En Escritos 2 (pp. 834-856). Buenos Aires: Siglo Veintiuno Editores (Trabajo originalmente publicado en 1966).

Lacan, J. (2003b). De una cuestión preliminar a todo tratamiento posible de las psicosis. En Escritos 2 (pp. 513-564). Buenos Aires: Siglo Veintiuno Editores (Trabajo originalmente publicado en 1959).

Lacan, J. (2006). El seminario de Jacques Lacan. Libro 23. El sinthome. Buenos Aires: Ed. Paidós (Seminario impartido en 1975).
Lacan, J. (2014). El seminario de Jacques Lacan. Libro 6. El deseo y su interpretación. Buenos Aires: Ed. Paidós (Seminario impartido en 1958).

Laforgue, R. (1926). Verdrängung und Skotomisation. International Zeitschrift für Psychoanalyse, XII (1), pp. 54-65.

Laforgue, R. (1927). Schizophrénie et schizonoïa. Revue Français de Psychanalyse, I, pp. 6-18.

Maleval, J. (2002). La forclusión del Nombre del Padre: El concepto y su clínica. Buenos Aires: Paidós.

Pichon, E. (1939). La famille devant M. Lacan. Revue Française de Psychanalyse, XI (1), pp. 107-135.

Roudinesco, E. (1994). Lacan. Esbozo de una vida, historia de un sistema de pensamiento. Buenos Aires: Fondo de Cultura Económica. 


\section{NOTAS}

1 Según el texto original en alemán: "Wir geben die einzelne Konstruktion für nichts anderes aus als für eine Vermutung, die auf Prüfung, Bestätigung oder Verwerfung wartet" (Freud, 1937/1961, p. 52).

2 Según el texto original en alemán: "Er verwarf das Neue -in unserem Falle aus Motiven der Kastrationsangst- und hielt am Alten fest. (Freud, 1918/1966, p. 111).

3 Según el texto original, en alemán: "Die dritte, älteste und tiefste, welche die Kastration einfach verworfen hatte, wobei das Urteil über ihre Realität noch nicht in Frage kam, war gewiß auch noch aktivierbar" (Freud, 1918/1966, p. 117).

4 Según el texto original en alemán: "Aus der Analyse des Angsttraumes entnehmen wir, daß die Verdrängung sich an die Erkenntnis der Kastration anschließt. Das Neue wird verworfen, weil seine Annahme den penis kosten würde" (Freud, 1918/1966, p. 144).

5 Según el texto original en alemán: "Die Neurose verleugnet die Realität nicht, sie will nur nichts von ihr wissen; die Psychose verleugnet sie und sucht sie zu ersetzen" (Freud, 1924/1967, p. 365)

6 Según el texto original en alemán: "Später einmal wird in der Urteilsverwerfung (Verurteilung) ein gutes Mittel gegen die Triebregung gefunden werden. Eine Vorstufe der Verurteilung, ein Mittelding zwischen Flucht und Verurteilung ist die Verdrängung, deren Begriff in der Zeit vor den psychoanalytischen Studien nicht aufgestellt werden konnte" (Freud, 1915/1945, p. 248).

$7 \quad$ Según el texto original en alemán: "Das Urteilen is die zweckmäßige Fortentwicklung der ursprünglich nach del Lustprinzip erfolgten Einbeziehung ins Icho der Ausstoßung aus dem Ich. Seine Polarität scheint der Gegensätlichkeit der beiden von uns angenommenen Triebgruppen zu entsprechen. Die Bejahung -als Ersatz der Vereinigung- gehört dem Eros an, die VerneinungNachfolge der Ausstoßung- dem Destruktionstrieb" (Freud, 1925/1948, p. 15).

8 "Il nous semble don établi que la notion de négation est en réalité absente de la pensé-langage du française de nous jours [...]" (Damourette y Pichon, 1930/1968, p. 146)

9 Un ejemplo dado por los autores es el siguiente: "Cela n'empèche pas qu'il ne soit mon ami" (Damourette y Pichon, 1930/1968, p. 133). En esta frase, el discrodantiel se ubica en la segunda parte de la frase. Su sentido es "eso no le impide ser mi amigo", pero en efecto, un intento de traducción literal advertiría que dice "eso no le impide no ser mi amigo".

10 "Le second morceau de la négation française, constitué par de mots comme rien, jamais, aucun, personne, plus, guère, etc., s'applique aux faits que le locuteur n'envisage pas comme faisant partie de la réalité" (Damourette y Pichon, 1930/1968, p. 138).

11 "Die Skotomisation bewirkt die Umkehrung der Polarität in den Lust und unlusterlebnissem, indem der eigentliche Schwerpunkt des Lebens, Vater, Mutter, Umwelt, aus dem Interessenkreis des Individuums ausgestoßen werden und dafür das eigene Ich an Stelle der lebendigen Umwelt tritt" (Laforgue, 1926, p. 61).

12 "La scotomisation conduit, en dépit des apparances, à la satisfaction du désir, non pas par l'intermédiare de la conscience, mais par l'intervention de réactions instinctives, avant lieu en dépit de la volonté du sujet, à l'insu de son contrôle conscient" (Laforgue, 1927, p. 14).

13 Según consta en el Index reféreéntiel (Krutzen, 2009), desde que introduce la forclusión, esta reaparece en su seminario en 11 ocasiones. En contrapartida, el término alemán es empleado, en el mismo período, en 28 oportunidades. 